\title{
Advancing Non-profit Organizations Through Technology and Informatization An analysis on improving the underdeveloped animal shelters and
rescues industry
}

\author{
Tianyu Zhang ${ }^{1}$ \\ ${ }^{1}$ Saint Stephen's Episcopal School, Nokomis, FL
}

\begin{abstract}
The situation at big for shelter animals in the US is improving. However, these animal shelters and rescues are overcrowded, and many animals get sick because of the unqualified hygiene conditions. The barriers that hinder the development of the non-profit industry of animal shelters and rescues are organization nature as non-profits, funding insufficiency, and lack of public relations strategies. Through technology, animal shelters and rescues can diversify their funding and adoption channels and actively raise awareness of animal protection among the public, leading to increasing motivation of adopting animals. This paper strives to present possible solutions and improvements through technology and informatization for the animal shelters and rescues industry.
\end{abstract}

\section{BACKGROUND}

The pet industry is an immense business in the current United States society. Larger firms like the Petsmart are seeing immense growth recently and probably will be seeing more in the coming years. According to the estimation from American Pet Products Association (APPA), within the year of $2020 \$ 75.38$ billion will be spent on pets in the US [1]. If the trend is not clear enough, IBISWorld reports that the average industry growth from 2015 to 2020 was $2.2 \%$ [2]. However, the wide spread and commonly known animal shelters and rescues, which are also involved firsthand in pet lives in America, have been mostly underdeveloped. Some of these non-profit organizations are even quite outmoded facilities in some areas.

The development of the non-profit industry of animal shelters and rescues has to be addressed, since roughly 6 million animals enter shelters and rescues each year [3]. Although many pet lovers do favor adopting dogs or cats from shelters and rescues instead of buying pets from shops as well as other owners, the system of these government funded establishments, or even some privately-owned animal rescues, are rather backward. Many kennels are years old with rust on the metal parts, and quite often, are not cleaned daily. Because of not enough funding and professional staff, there are times animal wounds or diseases are not treated on time. Bad hygiene therefore can result in bad health of the pets and in turn hurt the animals that were supposed to be "rescued".

According to the National Center for Biotechnology Information website (NCBI), the biggest problems facing animal shelters as well as rescues and the welfare of shelter animals today would be overcrowding which is caused by insufficient funding from either the government or local donators [4]. While funding insufficiency tie to problems that are not in us, the general public's ability to resolve, theoretically speaking there are still ways to at least improve situations in shelters and rescue firms.

This aim to answer the following questions: what are the development barriers of animal shelters and rescues? How technology, internet informatization, and data science can provide solutions for the development barriers of the non-profit industry in this highly modern and technological advanced world?

\section{URgenCy to IMPROVE ANIMAL SHELTER AND RESCUE PROGRAMS}

There are approximately 10,000 animal shelter and rescue groups in North America [5]. The current animal shelters and rescues have a general trend of live releases and adoptions. More and more people are willing to adopt homeless animals instead of buying them at profitable firms. However, the homeless animal problems are far from being well resolved. According to The Animal Society for the Prevention of Cruelty to Animals (ASPCA), approximately 1.5 million shelter animals are euthanized each year [6]. Looking at 2019 alone, 733,000 were euthanized [7]. A large number of animals is usually what caused these euthanize cases. Many shelters in the US, especially government funded ones, suffer from overcrowding due to limited funding have challenge providing sufficient facilities. 
The situation is, indeed, improving since more people adopt animals and actually keep them. However, the number of animals that enter shelters each year is not declining at all. At some point, a lot of the shelters and rescues are overcrowded. Animals had to be put down through euthanize methods, and the lack of good hygiene spread germs and diseases easily.

TABLE 1. Animal Shelters' Data For Dogs[8]

\begin{tabular}{|c|c|c|c|c|}
\hline Number & $\begin{array}{c}\text { Total } \\
\text { Number }\end{array}$ & $\begin{array}{c}\text { Lower } \\
\mathbf{9 5 \%}\end{array}$ & $\begin{array}{c}\text { Upper } \\
\mathbf{9 5 \%}\end{array}$ & $\begin{array}{c}\text { PetPoint } \\
\text { (2016) }\end{array}$ \\
\hline Shelters & 7076 & 6399 & 7890 & N/A \\
\hline $\begin{array}{c}\text { Total Dogs } \\
\text { Entering }\end{array}$ & $5,532,904$ & $5,003,528$ & $6,169,579$ & $4,171,017$ \\
\hline $\begin{array}{c}\text { Adopted } \\
\text { Dogs }\end{array}$ & $2,628,112$ & $2,376,660$ & $2,930,531$ & $2,302,829$ \\
\hline $\begin{array}{c}\text { Dog } \\
\text { Returned to } \\
\text { Owners }\end{array}$ & 969,443 & 876,689 & $1,080,998$ & 591,375 \\
\hline $\begin{array}{c}\text { Dogs } \\
\text { Transferred }\end{array}$ & 778,385 & 703,911 & 867,955 & 642,856 \\
\hline $\begin{array}{c}\text { Dogs } \\
\text { Euthanized }\end{array}$ & 776,970 & 702,631 & 866,366 & 592,255 \\
\hline
\end{tabular}

Table I is crated based on the national data presented by Woodruff \& Smith at the 2017 North America veterinary conference in Florida. It presents shelter animal data for over 1000 organizations in North America. As the table shows, the number one cause of shelter animals' deaths remains to be euthanasia. The problematic issue of overcrowding usually stem from and inability to hold large number of homeless animals at the shelter's facility. Once the number of animals stacks up, occasionally there would be cases where some are euthanized. Hygiene can also be a concerning cause of animals being euthanized. In some cases, bad hygiene due to reasons such as insufficient funding to renew the facility can cause severe diseases to erupt on some shelter animals, which leads to euthanasia if diseases become serious.

\section{BARRIERS FOR THE INDUSTRY DEVELOPMENT}

As one notices the underdevelopment of local animal shelters and rescues in the US, the most notable features are bad hygiene, lack of cleaning, not enough space and facilities for the shelter animals. Looking at the vast and advanced technologies in the world right now at this moment, one cannot help but notice how one of the most popular features in the US society, potential pet animals' welfare and rescue, is barely connected to any technologies. These problems with the animal shelters and rescues attribute to three factors: nature as nonprofit organization, funding insufficiency, and the system's lack of public relationship strategies.

\subsection{Animal Shelters and Rescues as Non-for- profit Organizations}

While animal shelters are all government-funded and animal rescues are sometimes privately funded, they are both operated as non-for-profit organizations. The challenges with non-for-profit organization's operation are personal, management, and program efficiency.

Both animal shelters and rescues rely heavily on volunteers. While funding can barely afford full time positions as long-term staff at a non-profit organization, the operation of an animal shelter or rescue needs volunteers' support. Volunteers come in with a warm heart, but not necessarily have relevant expertise to provide care and medical treatments to animals. Therefore, the outcomes of their services are hard to be guaranteed or improved. Moreover, volunteers are not paid, so animal shelters and rescues have challenges building accountability on personal.

In summary, animal shelters, and recues' nature as nonprofit organizations hinder their ability to increase funding. The amount of money at their disposal is generally unchanged each year, making it rather difficult for them to improve their facility.

\subsection{Funding insufficiency}

Secondly, the most essential barrier that cause problems such as overcrowding is the organization funding insufficiency. Either government funded shelters or privately-owned animal rescues are dependent on the surrounding areas' economic well-being. For shelters, the environment around it caused how much money local government will be able to fund, which then determine how big or how advanced of a facility will be built for the shelter. For private animal rescues, the area around it and its capitals is essential for how much money will be donated. The funding for these firms comes only from the donors in the area. This cause the shelter to have a much steadier facility with, generally speaking, more adoptions [9]. This led to the fact that government animal services account for roughly $45.5 \%$ of all animal intakes [10].

However, some privately owned rescues in well developed areas receives a lot more donation which gives them opportunities to improve their facility as much as possible. The two both have its advantages and benefits. However, both, as seen from the analysis above, also have flaws. Animal rescues, specifically, can be improved immensely if animals are being adopted at a quicker rate, since "more funding" is too broad of a statement. This leads to the third and last problem, the design of the system.

\subsection{Design of the system: Lack of Public Relations Strategies}

Thirdly, the public relations strategies of most shelters and rescues' animal adoption are traditional and underdeveloped. 
TABLE 2. Current and Potential Public Relations STRATEGIES OF ANIMAL SHELTERS AND RESCUES

\begin{tabular}{|l|l|}
\hline $\begin{array}{l}\text { How do people know } \\
\text { the animal shelters and } \\
\text { rescues? }\end{array}$ & $\begin{array}{l}\text { Where can people know about the } \\
\text { animal shelters and rescues? }\end{array}$ \\
$\begin{array}{l}\text { a. Basic } \\
\text { website info }\end{array}$ & $\begin{array}{l}\text { a. More detailed website } \\
\text { b. Happen to } \\
\text { pass by }\end{array}$ \\
$\begin{array}{l}\text { events Fundraisers/promotional } \\
\text { from someone } \\
\text { else c. Comprehensive }\end{array}$ \\
\end{tabular}

As shown in Table II, the basic channels that shelters and recues have to attract potential adopters are basic website info. Other adopters either happened to pass by the site or heard from someone else. These channels display a generally passive public relationship strategy from most shelters and rescues.

Some well-funded shelters and rescues might have a more complex system of publicity utilizing multiple media channels and social media platforms. However, most animal shelters and rescues, like shown in the left column in Figure 1, ends of applying only passive and basic public relations strategies. The basic information that's on most shelters and rescues' websites or social media pages is enough to attract people who have made up their mind to adopt. However, they do not attract the bigger group which are the people who haven't decided about adoption but are inclined to do so. These people will only decide to adopt when they see animals that impresses them. This impression cannot be done just with a simple profile, image or description. It needs heavy and detailed propaganda such as a story or a video, along with the basic descriptions.

In this, there is a lack of use of modern technology, which is quite off balance comparing to the currently highly technological world. Animal shelters and rescues operate at a face to face level where announcement and administration work are mostly carried out verbally. The websites for most shelters only carry out its basic function as a place to sign up and conduct simple searches of adoptable animals. There is not a diverse outreaching strategy to share apprehensive animal profiles. The shelters and rescues do not prepare and present animals as so adorable that people are provoked and inspired to adopt one at home.

The potential adopters come from the rather small group of people who did the research and saw the shelter on safari, its social media account, or from the people who know someone that is familiar with the organization. The shelters and rescues are usually just being passive. The ways they use to reach out to people are way to conventional in the modern-day world. The people now are highly engaged with cell phone, mobile applications and different social media platforms such as snapchat, Instagram, etc.. The traditional design of the adoption propaganda system really can be improved for most organizations.

\section{RECCOMENDATIONS FOR IMPROVEMENT}

The simple solution of "more funding" is empty talk. Furthermore, the organization type is obviously hard to be changed. However, there is a more profound approach which tackle the problem of funding and design of system indirectly through technology, internet, and big data.

\subsection{Increasing and raising funds}

Active outreaching to the community can substantially increase the publicity and in turn the potential funding of the shelters/rescues. The funding insufficiency for most shelters and rescues will need to be addressed with expertise on grant writing and fundraisers. With limited budgets, animal shelters and rescues will need to take advantage of social media and fundraising websites to spread information of the adoptable animals, which may otherwise be euthanized, to the target donors. Applying big data and marketing analytics, animal shelters and recues can identify potential donors and funding organizations who share the missions of animal protection.

Moreover, increasing the publicity through a comprehensive marketing plan may not directly attract all the animal lovers, but information can spread. Both off-line events and online campaigns can be organized, and people will be educated on animal protection and rescue. In addition, a community fundraiser can reach local residents and increase their knowledge about the animal shelter or rescue's location nearby [11].

If fund can be increased through the public events, the situation at shelters and rescues can be improved. More staff can be hired, especially for kennel cleaning and maintenance. If the kennels can be cleaned regularly, it would lower risks of disease. More staff also means that the dogs can be walked and trained more, which helps them to deliver a better impression when potential adopters visit and therefore be adopted quicker.

\subsection{Building an online outreaching system}

As mentioned earlier in the paper, technology and internet informatization are big parts of today's world and it seem rather odd that such important part of the society, homeless animal adoption and basic training at shelters, is farfetched from it. The conventional system of animal shelters and rescues carries out the whole process of volunteer dog walking quite traditionally. The important messages are delivered orally before each session. Other information possessed by the staff or shift leaders are also passed down orally and face to face. A high risk of flaws in the chain of communication arises.

However, if there is indeed an online system, the informatization would make these problems will no longer concerning. An online information database can be established, and people can access the important information on their own cell phone. If they missed the gathering before the session, they don't need to wander around the entire shelter looking for staff and shift leaders for important announcements. All they have to do is to look in their phone. All the dogs could also be provided with an 
electronic profile in the database. This means that bar codes could be set up at their kennels. Daily posts on social media about the dog and walker signing up to walk them could all be done easily.

For the adoption progress, the same benefit also applies, and arguably, works even better. The current system of outreaching and propaganda is quite underdeveloped as the ways are usually through simple social media posts or website descriptions that provide the most basic information on dogs. If technology expertise is available, there could potentially be an online system which posts dog information and activities every day. People would be able to see everything about the dogs from a firsthand source. There could be detailed descriptions on the dog with picture, words and videos. With this enhanced profile, potential adopters do not even have to go to the shelter to see the dogs for the first time. The online source can already provide a vivid image, which is detailed enough to attract adopters.

\section{ConClusion}

As funding could not be just simply increased by a fair amount for any shelters and rescues, getting an application and a detailed online database could be costly. The system also might need constant maintenance, which also requires technological staff and capitals.

On the other hand, if money is used on the technological aspects instead of portions such as further increasing the size of the campus, it could improve the current situation at that organization. Technology and internet informatization can vastly improve the efficiency and also attract more potential adopters and better match them with appropriate dogs.

Therefore, to improve the animal shelters and rescues, or the non-profit industry with similar development barriers, the organization leaders shall not stick with the current stage. Investing in applying technology and informatization to facilitate fundraising, donors and adopters' relations processes, and organization management strategies can be extremely helpful for the development of the non-profit industry.

\section{ACKNOWLEDGMENT}

The author hopes to acknowledge the support of Mrs. Chen, candidate of doctorate of education, who provided advisory in structuring the essay and academic writing.

\section{REFERENCES}

1. "Pet Industry Market Size \&amp; Ownership Statistics." American Pet Products Association, 2020, www.americanpetproducts.org/press_industrytrends. asp.

2. "Industry Market Research, Reports, and Statistics." IBISWorld, 2020, www.ibisworld.com/unitedstates/market-research-reports/pet-stores-industry/.

3. "Statistics." No Kill Advocacy Center, 2016, www.nokilladvocacycenter.org/statistics.html.
4. Andrew R, and Tamara K. "Dog Population \&amp; Dog Sheltering Trends in the United States of America." Animals: An Open Access Journal from MDPI, MDPI, 28 Apr. 2018, www.ncbi.nlm.nih.gov/pmc/articles/PMC5981279/.

5. "Pets by the Numbers." Animal Sheltering, 2019, www.animalsheltering.org/page/pets-by-thenumbers.

6. "Pet Statistics." ASPCA, ASPCA, 2018, www.aspca.org/animal-homelessness/shelter-intakeand-surrender/pet-statistics.

7. Ljubica v. "43 Animal Shelter Statistics \&amp; Facts That Will Shock You." Petpedia, 14 July 2020, petpedia.co/animal-shelter-statistics/.

8. Andrew R, and Tamara K. "Dog Population \&amp; Dog Sheltering Trends in the United States of America." Animals: an Open Access Journal from MDPI, MDPI, 28 Apr. 2018, www.ncbi.nlm.nih.gov/pmc/articles/PMC5981279/.

9. Suzie C. "Animal Rescue and Animal Shelter: What Is the Difference?" HomeoAnimal.com, 2019, www.homeoanimal.com/blogs/blog-pethealth/81114180-animal-rescue-and-animal-shelterwhat-is-the-difference.

10. Alex C, et al. "2018 Animal Sheltering Statistics." Shelter Animals Count | 2018 Animal Sheltering Statistics, 2018, shelteranimalscount.org/m/2018animal-sheltering-statistics.

11. Vladimir N. "5 Ways Animal Shelters Keep Their Doors Open (and How You Can Help).” PetMD, 21 Aug. 2015, www.petmd.com/dog/centers/nutrition/how-to-helpanimal-shelters-stay-open. 